\title{
PRELIMINARY RESULTS OF A RECOGNITION METHOD VISUALIZING THE AROMA AND FRAGRANCE FEATURES
}

\author{
K. KORÁNYa , Zs. MEDNYÁNSZKY and M. AMTMANN \\ Department of Food Chemistry and Human Nutrition, Szent István University, Faculty of Food Sciences \\ H-1118 Budapest, Somlói út 14-16. Hungary
}

(Received: 3 September 1999; accepted: 15 December 1999)

\begin{abstract}
The lack of interpretation methods capable of examining the aroma-profiles of spicy and medicinal plants and other samples of food origin (wines, honeys, fruits, fruit-distillates) makes necessary a thorough investigation of the relating evaluation procedures. By adding three appropriate hydrocarbon standards to all sample extracts, and measuring the programmed temperature retention indices of the components and normalizing the peak areas to that of the compound corresponding to the most intense chromatographic peak, a visualization of the aroma characteristics could be achieved. The relationship or identity of aroma patterns could be deduced from the presence or absence of similar polygons in the "constellation-maps" of the components.
\end{abstract}

Keywords: GC-MS identification, relative chromatograms, aroma-map, polygonalmethod

The aroma profile of wines, fruits, spicy and medicinal herbs is generally considered an important quality determining factor. While aroma profiles are highly characteristic and can be easily recognised by the expert, there are practically no general methods for their objective measurement. It is plausible that the taste/aroma of a product must be defined by a number of key components and their ratios (SHAATH \& GRIFFIN, 1988), on the other hand it is not a trivial task to determine which of the several hundred or thousand components, identifiable by GC or GC-MS, are crucial for the characteristic taste or aroma. The second type of difficulty comes from the fact that the ratio of crucial components may change upon storage or handling to such an extent that the product will in fact loose its characteristic sensory profile. Also, the extraction of the aroma materials will introduce an inevitable bias. The third source of problem is that of the analytical measurement, in this case extraction and gas chromatographic analysis.

Fortunately, if the aroma structures of the spicy and medicinal plants are genetically coded and determined, as is supposed and are therefore a fixed characteristic

${ }^{\text {a }}$ To whom the correspondence should be addressed

Phone: 36-1-372-6204; E-mail: kor6338@helka.iif.hu 
of each plant (EvANS, 1986), a method similar to the relative mass spectrum construction procedure might help to overcome the recognition problems of the chromatographic aroma patterns as well.

Most of the computerized GC equipment calculate the area percent of the peaks in a chromatographic run with ease and automatically, but the result depends on the sensitivity of the integration, namely on the integration parameters to too high an extent. The problem is analogous to the spectral interpretation difficulties in mass-spectrometry (KAMEOKA, 1986) and the correct solution is absolutely similar as well. Transforming the absolute chromatograms (retention time vs. peak areas) into relative ones can ensure nearly distortion-free measurement of the compound ratios in the linearity range of the instrument and can also compensate for any effect of sample preparation to an extent not worse than the internal standard method. A considerable advantage of this conversion is that the normalizing reference compound behaves like a natural internal standard so that variations due to sample preparation and gas chromatography conditions are largely overcome (RAPP, 1988). These relative chromatograms have the same advantages as relative mass spectra compared to the corresponding absolute ones and can be handled identically from mathematical point of view.

Another difficulty is the creation of an "absolute $\mathrm{x}$-axis", since the retention time is highly dependent on the gas chromatographic parameters and is not a unique function of structure (KOBAYASHI \& KAWAKAMI, 1991). Totally different compounds may have the same retention time on the same column under different conditions. In gas chromatography at constant speed column heating the members of homologous series (n-alkanes, olefins...etc.) elute equidistantly, their reduced retention times define a straight line as a function of carbon number. For expansion of the horizontal axis scale not the carbon numbers themselves, but their hundredfold values $(1000,1100, \ldots 2000)$ are used. The parameters (slope and offset) are characteristic of the stationary phase and are constant if relative retention times (RRT $=$ reduced retention time divided by that of the longest n-alkane) are used for calculation. In practice three properly chosen nhydrocarbons (no coincidence of peaks) are enough to determine the equation of the linear function. Since RRTs can be calculated for all compounds eluting with the alkanes in the same chromatographic run and all of them lie on the straight line of the nhydrocarbons, their " $\mathrm{x}$ "-co-ordinates in other words their places can be determined by the equation. The method described is called programmed temperature retention index (PTRI) measurement.

\section{Materials and methods}

Chemical substances, standards and solvents used in our work were of "analytical", "HPLC" or "GC" grade, and were purchased from Merck (Darmstadt, Germany), Carlo Erba (Milan, Italy) and Carl Roth (Karlsruhe, Germany). Although 
spectral transparency is not equivalent to chemical purity, transmittance values of $90 \%$ at $200 \mathrm{~nm}$ wavelength do indicate the high quality of solvents.

\subsection{Solvents and chemicals}

n-Pentane, iso-Octane, bidistilled water, ethanol, normal-hydrocarbon standards .

\subsection{Glassware and tools}

The glassware was of thermoresistant Pyrex quality. Distillation equipment and other glass tubes were teflon-valve equipped.

Round bottom flasks $\left(1 \mathrm{dm}^{3}\right)$, distillation equipment with condenser, tefloncapped sample containers.

\subsection{Instrumentation}

Hewlett Packard 5890/II GC - 5971/A MSD (Palo Alto, CA, USA).

\subsection{Samples}

Honey (acacia), herbs (lavender), must of known origin and provenance, provided by courtesy of farmers and primary producers, were examined. They are as follows:

- Muscat Ottonel must from Gyöngyös region,

- acacia (Robinia pseudoacacia) honeys from the western border, Visegrád, Cserhát, and Alföld regions of Hungary,

- lavender (Lavandula angustifolia Mill.) herbs from the experimental farm of the University of Horticulture and Food Industry.

The herb samples were kept at $5{ }^{\circ} \mathrm{C}$ in aroma-tight bags excluding light. Before taking the quantity to be ground, the whole sample was homogenized by mixing. Grinding of the $250 \mathrm{~g}$ plant sample was performed by a laboratory mill, Lab. Mill-1 QC114 (Labor MIM., Budapest, Hungary). Distillation was carried out immediately after grinding to minimise the loss of the most volatile compounds.

For steam distillation of all plants the same method was used. To gain results most representative of the samples, $3 \times 75 \mathrm{~g}$ of the herbs were distilled separately and each distillate was measured by GC in 3 parallel injections, having diluted the collected essential oils with iso-octane containing the $\mathrm{C}_{10}, \mathrm{C}_{14}$ and $\mathrm{C}_{20}$ n-hydrocarbon standards. The average of the 9 runs was calculated.

The preparation of the wine samples needed a combination of distillation and extraction. In the first step the volatiles together with the alcohol of $500 \mathrm{~cm}^{3}$ wine were distilled resulting in $80 \mathrm{~cm}^{3}$ of condensate, i.e. a volume representing more than $150 \%$ of the ethanol content. Prior to the distillation $100 \mathrm{~g} \mathrm{NaCl}$ was added to the sample to increase the 
volatility of the aroma compounds. Distillates of $3 \times 500 \mathrm{~cm}^{3}$ of the same wine were combined and extracted by $3 \times 80 \mathrm{~cm}^{3} \mathrm{n}$-pentane. Then the pentane extract was evaporated to $0.5 \mathrm{~cm}^{3}$ in a cold $\mathrm{N}_{2}$ stream and made up to $1 \mathrm{~cm}^{3}$ with iso-octane containing the $\mathrm{C}_{10}, \mathrm{C}_{14}$ and $\mathrm{C}_{20} \mathrm{n}$ hydrocarbon standards. The samples were analyzed by gas chromatography in 5 parallel injections and the average of the 5 runs was calculated.

In the case of honey samples a preparatory method similar to that of the wines was applied. A $600 \mathrm{~g}$ sample of the honeys was dissolved and made up to $1 \mathrm{dm}^{3}$ in bidistilled water. One third of the solution was diluted to $500 \mathrm{~cm}^{3}$ with $50 \mathrm{~cm}^{3}$ of ethanol (acting as scavenger substance) and the remainder by water. Then the volatiles together with the alcohol were distilled resulting in $80 \mathrm{~cm}^{3}$ of condensate. Subsequent treatment and measurement used the same methods that were discussed in the previous paragraph (wine samples).

The GC-MS measurements were performed under the following conditions:

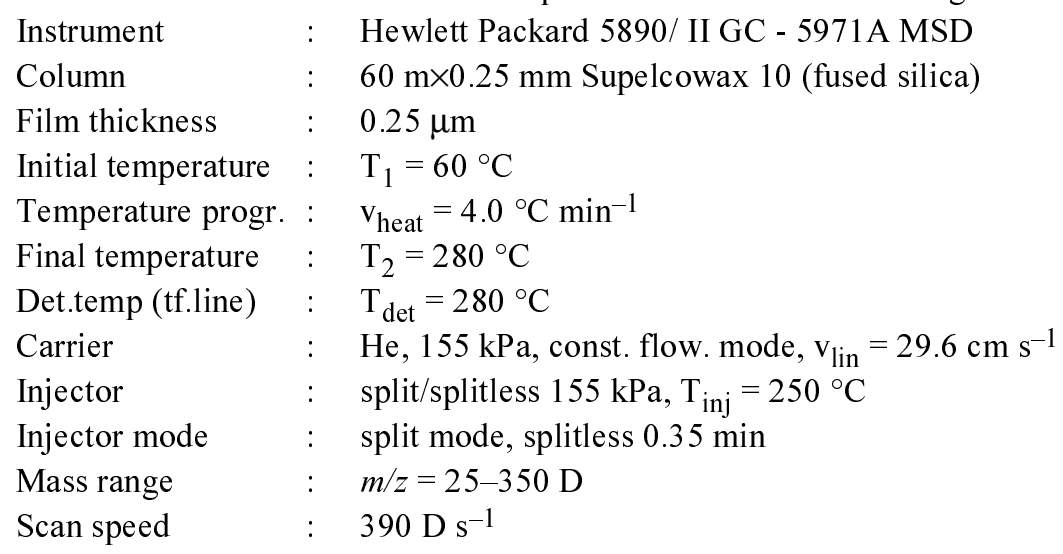

\section{Results}

In developing the aroma-map construction method, the retention times were converted into PTRIs. The reproducibility of the PRTI values is \pm 3 index units with respect to the mean. The peak areas were transformed into relative intensity data dividing the individual areas by that of the largest peak (ethyl-hexadecanoate (honeys), linalool (Lavender), l-alpha-terpineol (Muscat Ottonel-musts)). For minor components (under 3 rel. \%) the reproducibility of relative intensities is approximately $\pm 10 \%$, for medium components (3-8 rel. \%) it is between $\pm 5-8 \%$ and for major constituents (above 8 rel. \%) it is lower than $\pm 5 \%$ (all values are given in rel. \% of the mean value determined for a compound in question). 
Table 1

List of identified compounds with their programmed temperature retention indices

\begin{tabular}{|c|c|c|c|}
\hline Index & Compound & Index & Compound \\
\hline 945 & Ethane, 1,1-diethoxy- & 1355 & 3-Hexen-1-ol \\
\hline 967 & 2,4,5-trimethyl-1,3-dioxolane & 1382 & Octene-1-ol-acetate \\
\hline 988 & Butane, 1,1-diethoxy & 1391 & 3-Octanol \\
\hline 1020 & alpha-Pinene & 1422 & Butanoic ac.hexyl ester \\
\hline 1057 & Camphene & 1433 & hexyl-2-Me-Butyrate \\
\hline 1095 & beta-Pinene & 1436 & Octanoic acid, ethyl ester \\
\hline 1030 & Butanoic acid, ethyl ester & 1440 & p-Mentha-1,5,8,-triene \\
\hline 1062 & 1-Propanol, 2-methyl- & 1443 & Hexadecane, 2,6,10,14-tetramethyl- \\
\hline 1091 & Pentane, 1-(1-ethoxyethoxy)- & 1446 & Linalool-oxide (2) \\
\hline 1108 & 1-Butanol, 3-methyl-, acetate & 1447 & Benzene, 1-isopropenyl-?-methyl- \\
\hline 1136 & delta-3-Carene & 1452 & Linalool oxide (2, deriv.) \\
\hline 1138 & alpha-Terpinene & 1452 & 1-alpha-Terpineol deriv. \\
\hline 1149 & beta-Myrcene & 1453 & Naphtalene, 1,2,3,4-tetrahydro-1,1,6-trimethyl- \\
\hline 1166 & alpha-Terpinolene & 1453 & p-Mentha-1,5,8-triene \\
\hline 1187 & Dodecane & 1456 & 1,2,3,4-thydr-1,1,6-triMe-Naphthalenene \\
\hline 1189 & dl-Limonene & 1470 & trans-Sabinenehydrate \\
\hline 1190 & 1-Butanol, 3-methyl- (impure) & 1472 & Linalooloxide (deriv.) \\
\hline 1199 & 1,8-Cineole & 1473 & Neroloxide (deriv.) \\
\hline 1213 & $\begin{array}{l}\text { 7,7-diMe-2-Methoxy- } \\
\text { norborn-2-ene }\end{array}$ & 1477 & Geraniol (deriv.) \\
\hline 1222 & Hexanoic acid, ethyl ester & 1479 & Neroloxide (deriv.) \\
\hline 1226 & 1,3,6-Octatriene..... & 1480 & Linalool oxide (deriv.) \\
\hline 1232 & 1-Dodecene & 1506 & Pentadecane \\
\hline 1238 & gamma-Terpinene & 1509 & Geraniol (deriv.B) \\
\hline 1245 & 1,3,7-Octatriene,3,7-dimethyl- & 1537 & Benzaldehyde \\
\hline 1250 & 3-Octanone & 1537 & Camphor \\
\hline 1262 & Acetic acid, hexyl ester & 1545 & Nonanoic acid, ethyl ester \\
\hline 1267 & $\begin{array}{l}\text { Benzene, 1-methyl-4- } \\
\text { (1-methylethyl)- }\end{array}$ & 1553 & Linalool \\
\hline 1267 & Hexylacetate & 1560 & 1-Octanol \\
\hline 1280 & alpha-Terpinolene & 1568 & Linalyl acetate \\
\hline 1293 & Tridecane & 1574 & 1,3-diMe-bicyclo[3.3.0.]... \\
\hline 1297 & $\begin{array}{l}\text { Cyclohexane, } \\
\text { 1,2,4-tris(methylene)- }\end{array}$ & 1597 & Bornyl formate \\
\hline 1314 & Linalool (deriv.) & 1611 & 3-Cyclohexene-1-ol.. \\
\hline 1337 & $\begin{array}{l}\text { Propanoic acid, 2-hydroxy-, } \\
\text { ethyl ester }\end{array}$ & 1612 & Hotrienol \\
\hline
\end{tabular}


Table 1. contd.

\begin{tabular}{|c|c|c|c|}
\hline Index & Compound & Index & Compound \\
\hline 1339 & Propanoic acid hexyl ester & 1616 & trans-Caryophyllene \\
\hline 1342 & Propanoic ac.,2-Me-octyl ester & 1629 & 1-Me-4-(1-MeEthenyl)-Cyclohexanol \\
\hline 1348 & 1-Hexanol & 1632 & Decanoic acid, ethyl ester \\
\hline 1640 & 5,7-Octadien-2-ol, 2,6-dimethyl- & 1896 & 3-Octadecene, (E)- \\
\hline 1642 & Decanoic acid, ethyl ester & 1906 & N-Acetyl-N'-phenylhydrazine \\
\hline 1645 & Tricyclene(deriv.) & 2009 & Lavender-(Z) \\
\hline 1649 & 1-Hexadecene & 1933 & beta.-Terpinene \\
\hline 1657 & 1-Nonanol & 2014 & 2-Tridecanone \\
\hline 1663 & gamma.-Terpinene & 2049 & Tetradecanoic acid, ethyl ester \\
\hline 1666 & (Z)-beta-Farnesene & 2117 & Heneicosane \\
\hline 1668 & Tricyclene & 2150 & 2-Pentadecanone, 6,10,14-trimethyl- \\
\hline 1675 & (-)-Lavandulol & 2265 & Docosane \\
\hline 1685 & 1H-Pyrazole,3,5-diMe... & 2304 & (+-)-15-Hexadecanolide \\
\hline 1696 & 3-Cyclohexene-1-methanol... & 2351 & Hexadecanoic acid, thyl ester \\
\hline 1771 & Ethanone, 1-(methylphenyl)- & 1697 & 1-alpha-Terpineol \\
\hline 1786 & Benzaldehyde,4-(1-MeEt)- & 1701 & endo-Borneol \\
\hline 1790 & $\begin{array}{l}\text { Benzene, } \\
\text { 1-(1,1-dimethylethyl)-3-meth }\end{array}$ & 1715 & Bicyclo[4.4.0]dec-1-en, 2-isopropyl- \\
\hline 1799 & Acetic acid, 2-phenylethyl ester & 1721 & p-Mentha-1(7),2-dien-8-ol \\
\hline 1811 & beta.-Damascenone & 1721 & Epoxylinalol \\
\hline 1816 & trans-2-Caren-4-ol & 1721 & Nerylacetate \\
\hline 1824 & cis-Carveol & 1740 & 2-Cyclohexene-1-one \\
\hline 1826 & Dodecanoic acid, ethyl ester & 1740 & beta.-Citronellol \\
\hline 1826 & Hexanoic acid & 1747 & Geranylacetate \\
\hline 1830 & trans-Geraniol & 1748 & Naphthalene \\
\hline 1880 & Nonadecane & 1755 & Nerol \\
\hline 1890 & Benzeneethanol & 1762 & Naphthalene, $1,2,3,4-.$. octahydro... \\
\hline
\end{tabular}

For reasons of space, no GC/MS data are shown. The list of identified compounds is shown in Table 1, which also contains the PTRIs measurable under the experimental conditions.

The diagrams constructed by the above process can be interpreted rather in a "star-map" than a spectrum-like manner. For example three representative aroma-maps are shown in Figs. 1, 2 and 3. 


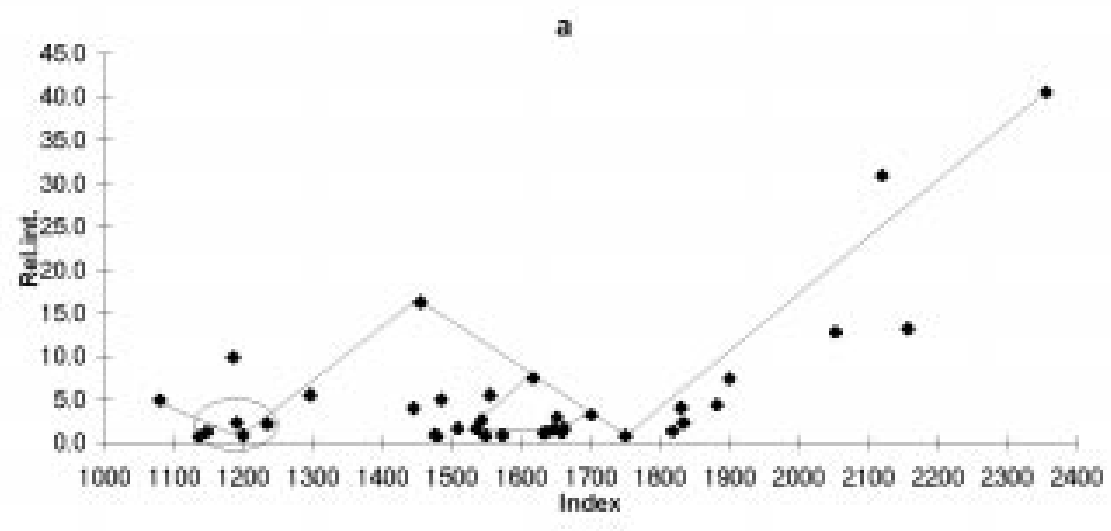

b

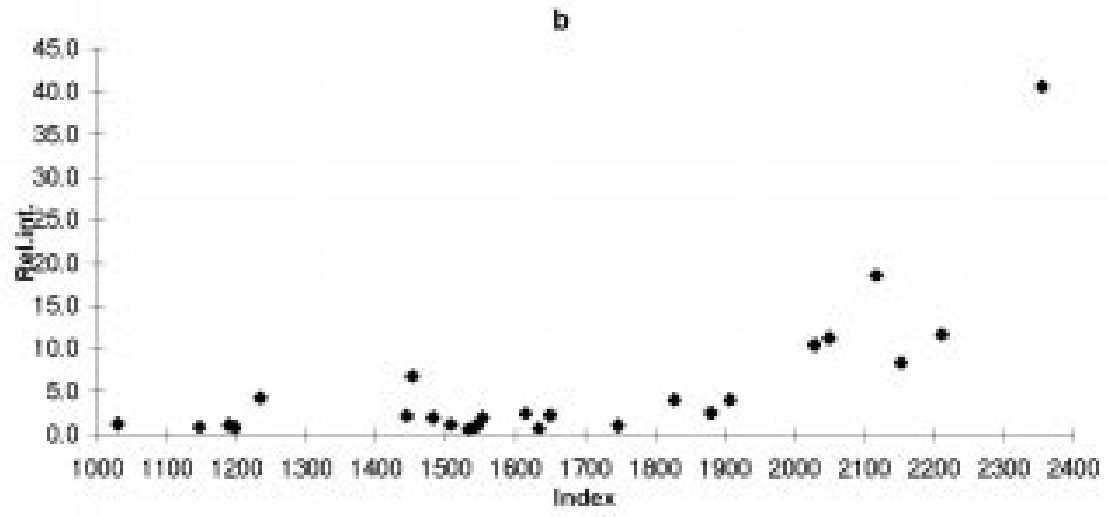

$c$

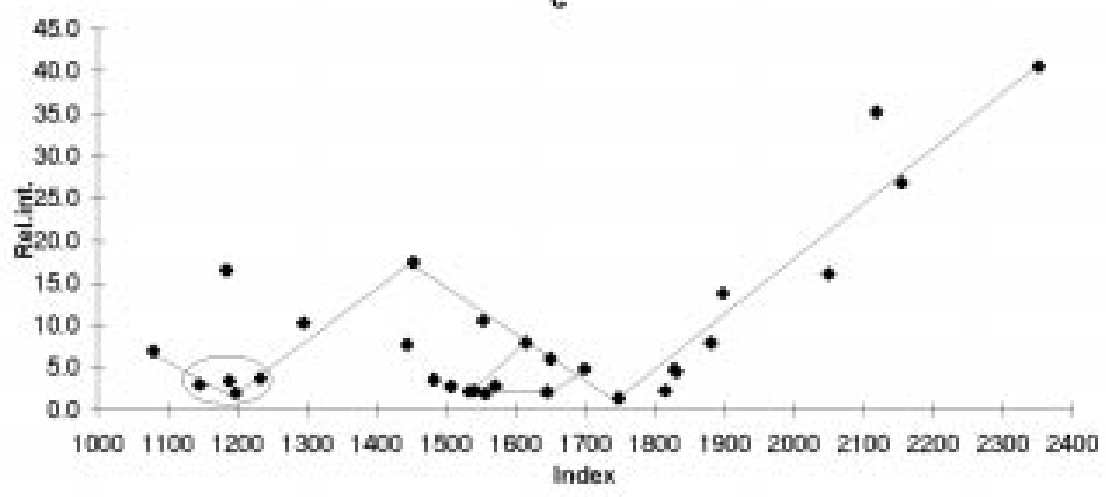

Fig. 1. The constellation map of acacia honeys. a. Acacia honey (western border of Hungary); b. acacia honey (Kecskemét region) (non characteristic of acacia); c. acacia honey (Cserhát region) 

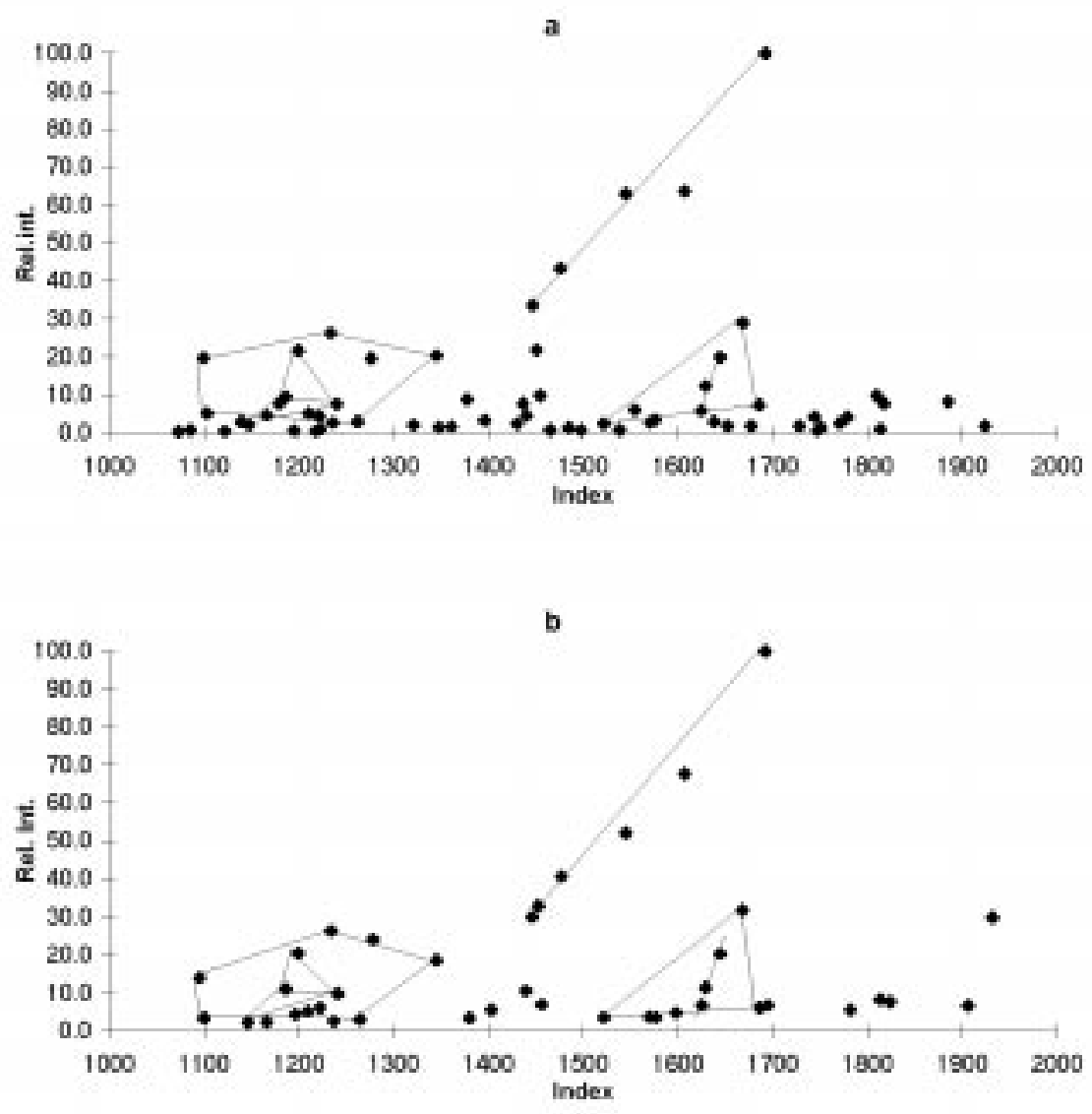

Fig. 2. The constellation map of Muscat Ottonel musts. a. Muscat Ottonel must ` 96 ; b. Muscat Ottonel must ` 97

The aroma-maps of Fig. 1 show the comparison of three acacia honeys. The characteristic ones "a" and "c" derive from Nagykanizsa (western border of Hungary) and Cserhát (North-West Hungary) regions. They were produced by a primary producer collaborating with us on our research. The third honey ("b") was purchased from an unknown producer and was told to originate from Kecskemét (Plains of Hungary) region. We found it to be non characteristic of other acacia honeys. 

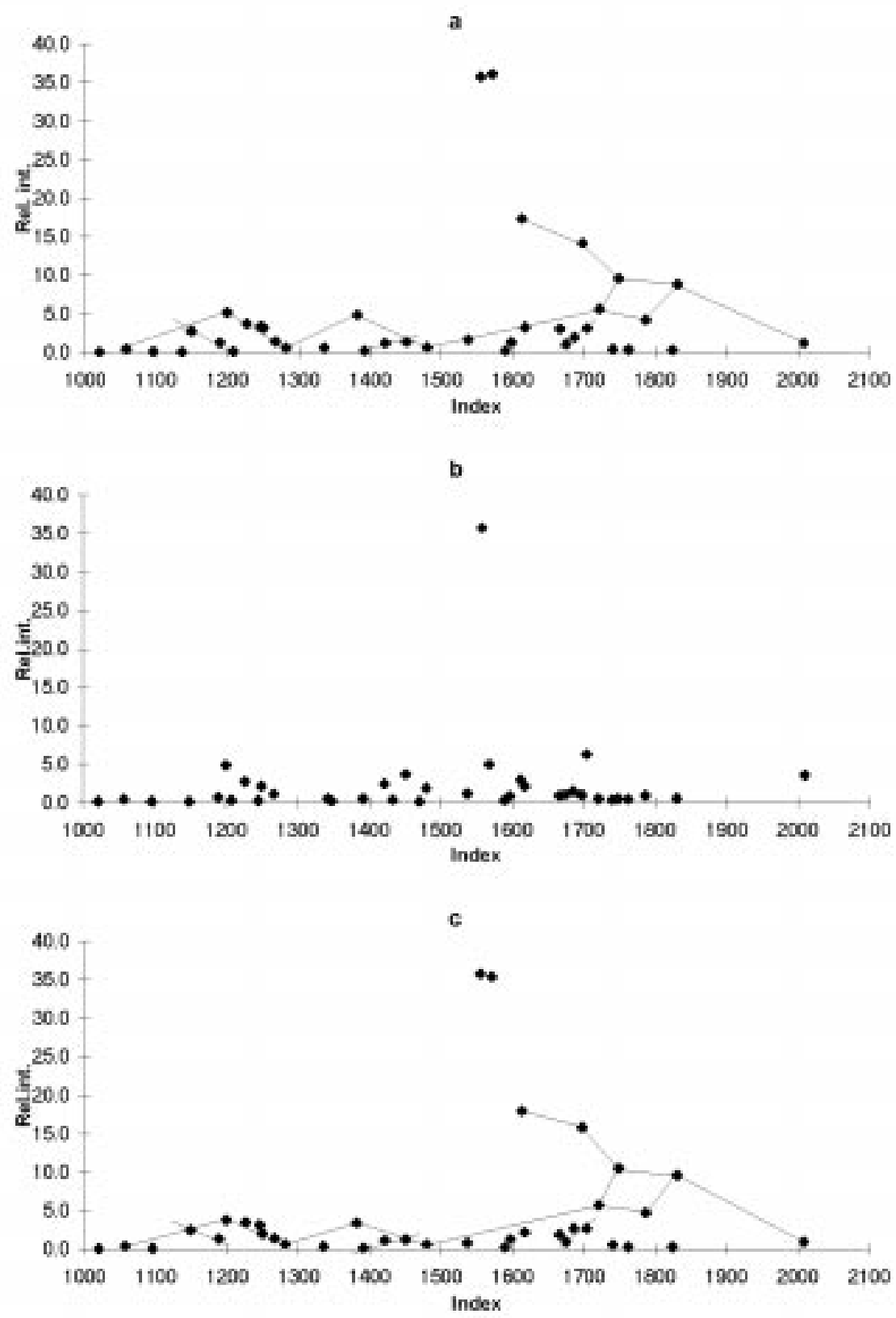

Fig. 3. The constellation map of lavenders. a. Lavender 1102; b. lavender 1107; c. lavender 1105 
Relative chromatograms on Fig. 2 depict the aroma maps of Muscat Ottonel musts deriving from vintages 1996 ("a") and 1997 ("b"). Appart from observable differences the great similarity is obvious. The must samples were produced by the same primary producer in Gyöngyös (traditional wine producing district of North-East Hungary) region in both years.

Aroma-maps on Fig. 3 show the comparison of lavenders. In an experiment among six samples investigated 4 were members of the same cultivated variety (relative herbs) grown under slightly different conditions. Two of them were non-relatives. Relatives showed a special, "Ursa Major"-like structure whilst non-relatives did not. The figure depicts the aroma map of a non relative lavender ("b") between two relative ("a" and "c") ones. Samples derived from the pilot farm of the University of Horticulture and Food Industry.

\section{Discussion}

The thorough study on the honey, grape-must and lavender records discovered characteristic differences in every region of the chromatograms, but the detailed chromatograms would require too much room to be published. These studies demonstrated that a safe distinction can be made between any two same-type samples by visual evaluation of the relevant chromatograms, a conclusion that is not new, however.

The greatest disadvantage of relative retention time versus relative intensity diagrams used in our previous pepper-aroma research work (KORÁNY \& AMTMANN, 1997) was that the meaning of the " $x$ "-axis changed from sample type to sample type. As the retention time reference compounds were different in the pepper, wine, paprika, honey, medicinal herb, etc. samples, the relative retention time values had chemical information only within the diagram series of the same type of samples, and the aromaspectra of the different samples (e.g. honey to wine or pepper to paprika etc.) were not comparable. The real problem was whether a general, always applicable, solution of classification and recognition existed or not. To answer the above question a new graphic procedure, the relative aroma-chromatogram construction method has been tried. In our work substitution of retention times depending on gas chromatographic conditions was performed by determining the relative position of the compounds related to normal $\mathrm{C}_{10}, \mathrm{C}_{14}$ and $\mathrm{C}_{20}$ standards.

At first sight differences are dominant among the aroma-maps of the same-type samples, too (see Figs. 1, 2 and 3), but the thorough visual study of the figures brings an unexpected result. Similar patterns, polygons and straight lines occure in the diagrams. The explanation of this phenomenon is really hard because the amounts of fragrance compounds are influenced by so many factors, e.g. composition of soil, sunny 
hours/year, annual rainfall, weather just prior to harvest, etc. On the other hand it is supposed, that the ratios of the main aroma and fragrance components of the plants are genetically coded and determined and are therefore a fixed characteristic of each plant. Obviously normalization suggests an overall and constant measurement efficiency for all components that is not necessarily the case, but the method does give good results in our hands. We assume, the method has found those substances the ratios of which do not change with the growing conditions. That could be a logical explanation for the occurrence of similar patterns in the aroma-maps.

Since the relationship or identity of the aroma characteristics causes the occurrence of very similar or the same "constellations" in the set of points, the identification can be performed precisely by searching for and finding similar polygons. No similarities can be observed among aroma-maps of different sample extracts nor among unrelated same-type samples, e.g. characteristic and non-characteristic acacia honeys, relative and non-relative lavenders, etc.

\section{Conclusions}

The present work contributes to the development of a method for the graphic recognition and identification of aroma patterns, and the following tasks were worked out: (a) the elaboration of sample preparation methods producing extracts that represent the samples' real aroma-character, (b) determination of the optimal GC separation conditions of flavour and fragrance compounds, (c) creation of a stationary phase dependent "absolute" $\mathrm{x}$-axis by measuring the PTRIs in each chromatograhic run, (d) the identification of as many compounds as possible and matching the chemical structures to PTRIs by GC-MS, (e) conducting aroma extract identification experiments by the construction of "constellation-maps".

The "polygonal" method has proved its abilities in the recognition and identification of honeys, wines, grape-musts and herb essential oils by providing ready visualisation of the aroma properties. The run by run PTRI determination and peak area normalization lead to nearly distortion-free measurement of the compound ratios, that are much more characteristic of the aroma patterns than the absolute amounts themselves. They also make possible sample identification by using an ordinary FIDequipped gas-chromatograph, because the degree of relationship or identity of the samples can be deduced from the presence of similar polygons. These measurements applying relative mass-spectra construction principals promise the possibility of paprika variety identification too, that is of primary importance in Hungarian red pepper production and export. 


\section{References}

EvANS, W. C. (1996): Chemical races, chemodemes. -in: Trease and Evans' pharmacognosy. WB Saunders Company Ltd., pp. 90-93.

KAMEOKA, H. (1986): GC-MS method for volatile flavor components of food. -in: LINSKENS, H. F. \& JACKSON, J. F. (Eds) Gas chromatography/mass spectrometry. Modern methods of plant analysis new series, Vol.3. Springer Verlag, Berlin, Heidelberg, New York, Tokio, pp. 254-276.

KOBAYASHI, A. \& KAWAKAMI, M. (1991): Analysis of essential oils of tea. -in: LINSKENS, H. F. \& JACKSON, J. F. (Eds) Essential oils and waxes. Modern methods of plant analysis new series, Vol. 12. Springer Verlag, Berlin, Heidelberg, New York, Tokio, pp. 21-40.

KORÁNY, K. \& AMTMANN, M. (1997): Gas chromatography/mass spectrometry measurements in the investigation of pepper aroma structures. Rapid Communications in Mass Spectrometry, $11,686-690$.

RAPP, A. (1988): Wine aroma substances from gas chromatographic analysis. -in: LINSKENS, H. F. \& JACKSON, J. F. (Eds) Wine analysis. Modern methods of plant analysis new series, Vol. 6. Springer Verlag, Berlin, Heidelberg, New York, Tokio, pp. 29-66.

SHAATH, N. A. \& GRIFFIN, P. M. (1988): Modern analytical techniques in the flavor industry. -in: CHARALAMBOUS, G. (Ed.) Frontiers of flavor. Developments in food science, Vol. 17. Elsevier, Amsterdam, Oxford, New York, Tokyo, pp. 89-107. 